\title{
Formation of carbonate of lime under the influence of sugar
}

\section{Pelouze}

To cite this article: M. Pelouze (1832) Formation of carbonate of lime under the influence of sugar, Philosophical Magazine Series 3, 1:1, 84-85, DOI: $10.1080 / 14786443208647832$

To link to this article: http://dx.doi.org/10.1080/14786443208647832

曲 Published online: 01 Jun 2009.

Submit your article to this journal ¿

Џll Article views: 2

Q View related articles $\sqsubset$ 
Forty parts of this acid having been exposed for an instant to a considerable heat, they fused, swelled up, and left after cooling a dry yellowish matter, which was transparent like gum, and weighed $\mathbf{3 6 . 5}$ parts. This substance when softened by heat acquired great ductility, which allowed it to be drawn into threads as fine as hairs.

This change of form, which recalls the dimorphism of sulphur, shows either a new molecular arrangement, or another isomerical modification. In fact, the tartaric acid thus submitted to the action of heat, no longer possesses its original properties; it is uncrystallizable, and is merely a thick viscid mucilage, which attracts moisture from the air.

If this substance be dissolved in hot water, and carbonate of lime be gradually added to saturate it, it does not form, as with common tartaric acid, a sandy deposit of crystallized tartrate of lime, but the solution becomes gradually turbid as it cools, and deposits a mucilaginous transparent insipid mass, which forms threads between the fingers like turpentire. This calcareous salt when dried is unalterable in the air, and resembles gumarabic. When heated in water or weak acetic acid, it softens, resuming its viscid and adhesive properties, without being sensibly dissolved; an excess of acid, however, redissolves it, especially when hot, and by evaporating the solution to dryness, there remains a dry brittle acidulous substance, which is transparent like a varnish, is unalterable by the air, and which when immersed for some time in cold water seems to undergo a molecular motion, which reproduces tartaric acid in its original state, for then there separates a sandy deposit of common tartrate of lime.

Tartaric acid modified by heat, also dissolves magnesia and yields a bitter liquor, which leaves a varnished surface by evaporation. Crystallized tartaric acid acts quite differently with this earth, for it immediately precipitates a white powder, which is difficultly soluble in water; the same modified acid, saturated with soda, produces an uncrystallizable mucilaginous combination, which attracts moisture from the air.

With potash an analogous result is obtained; and if to the compound an acid be added in excess, a very greatly divided precipitate is formed, as difficultly soluble as tartar, but which has not its granular appearance. When redissolved in hot water, it gives by cooling white opake plates, in which rudiments of crystals are scarcely discernible; this acidulous salt when saturated with soda gives a salt analogous to Rochelle salt. Although tartaric acid, when exposed to heat, is not a very permanent isomeric substance, it evinces at least a remarkable tendency to this state. - Ann. de Chim. et de Phys. xlviii. 299.

FORMATION OF CARBONATE OF LIME UNDER THE INFLUENCE of SUGAR. bY M. PELOUze.

Mr. Daniell concluded from his experiments, that when lime is dissolved in an aqueous solution of sugar, the sugar is decom- 
posed, and converted into mucilaginous matter, while the lime is precipitated in the state of carbonate, and crystallized in very acute rhomboids. M. Becquerel obtained the same crystals, under the influence of weak electrical currents; and as he operated without the contact of air, the decomposition of sugar was undoubtedly effected, under the circumstances in which it was placed.

M. Pelouze concludes from new experiments which he has made on this subject, that when the mixture is exposed to the air, the sugar is not decomposed, and that the crystals which are produced, result from the action of the carbonic acid of the atmosphere upon the lime; and the carbonate forming slowly in a fluid, is deposited with water of crystallization. It contains 5 atoms of water; at about $86^{\circ}$ of Fahrenheit it loses its water of crystallization and becomes pasty; but what is very remarkable is, that the salt which is perfectly dehydrated at $86^{\circ}$ when it is in water, loses only 2 atoms when it is heated in strong alcohol at a boiling heat. The new salt containing 3 atoms of water is efflorescent in the air, while that with 5 atoms undergoes no alteration.-Journal de Pharmacie, April 1832.

\section{EXTEMPORANEOUS SOLUTION OF CHLORINE.}

M. Tourtois gives the following quantities of ingredients for obtaining a solution of chlorine, which are to be added to an imperial quart of water and well shaken together in a stopped bottle; and he remarks that unless the deutoxide of lead be finely powdered, some of it will remain undecomposed:-

$$
\begin{aligned}
& \text { Sulphuric acid } \ldots \ldots \ldots 910 \text { grains } \\
& \text { Common salt } \ldots \ldots 280 \\
& \text { Deutoxide of lead } \ldots \ldots \text { - Ibid. }
\end{aligned}
$$

As, however, 280 of common salt contain 112 of sodium, requiring nearly 38 of oxygen for conversion into soda, and as 116 of deutoxide of lead give out only 4 of oxygen by reduction to protoxide, it will appear by calculation that 1102 grains of red-lead should be used with 280 of salt, instead of only 840 . The sulphuric acid must be equivalent to 150 of soda and 1064 of protoxide of lead, or about 700 grains, instead of 910 . R. P.

\section{SEPARATION OF PEROXIDE OF IRON FROM PROTOXIDE OF MANGANESE. BY M. LIEBIG.}

When carbonate of lime is boiled with a solution of peroxide of iron and protoxide of manganese, the former is precipitated, and the latter remains in solution; the separation is so complete that no trace of iron remains in solution, nor is any manganese precipitated.

Carbonate of magnesia may be employed for the same purpose. To determine the precision of this method, one part of protosulphate of manganese was mixed with forty parts of protosulphate of iron, and mixtures were made in inverse proportions; after having peroxidized the iron by nitric acid, the sulutions were boiled with carbonate of magnesia. 